\title{
Using electron backscatter diffraction patterns to examine recrystallization in polar ice sheets
}

\author{
Rachel OBBARD, Ian BAKER, Katherine SIEG \\ Thayer School of Engineering, Dartmouth College, Hanover, NH 03755-8000, USA \\ E-mail: rachel.w.obbard.th06@alum.dartmouth.org
}

\begin{abstract}
The fabric of polycrystalline ice is typically described using the $c$-axis orientation alone, but this is insufficient for a full description of grain orientations in this hexagonal material. Electron backscatter diffraction (EBSD) provides full $c$ - and a-axis orientation of individual grains, and is used here to study Greenland Ice Sheet Project 2 (GISP2) ice specimens from depths of 1551, 1642 and $1745 \mathrm{~m}$. Complete orientation data are used to compare nearest-neighbor relationships to overall fabric and to differentiate between recrystallization mechanisms. Changes in orientation between grains and subgrains in GISP2 specimens were correlated with the appearance of grain boundaries on thin sections and used to identify grain sets that were probably produced by polygonization. Comparison of grain misorientations that take into account both $c$ - and a-axis differences with those derived from $c$-axis directions alone reveals the presence of polygonization and illustrates the usefulness of this technique.
\end{abstract}

\section{INTRODUCTION}

The microstructures of polar ice sheets arise from the environmental and stress conditions that they experience and also affect their dynamic behavior (Azuma and Higashi, 1985; Alley, 1988; Budd and Jacka, 1989). By studying the texture (grain size and shape) and fabric (orientation) of the polycrystalline ice, we can better understand ice-sheet rheology, calculate more accurately the age/depth relationships that allow the ice-core record to be used to study climate change, and develop improved flow models to predict ice-sheet movement (Gow and Williamson, 1976; Gow and others, 1997).

As in other polycrystalline materials, some grains grow at the expense of others in order to reduce the overall grainboundary energy, leading to an increase in average grain size (Porter and Easterling, 1993). In glaciers, the average grain area increases linearly with age under relatively isothermal conditions in the upper part of the core (Alley and others, 1986). Yet in many cores, grain growth appears to stop at a depth unmarked by changes in other physical properties, such as temperature, impurity content or fabric type, a phenomenon documented at Byrd Station, Antarctica (Gow and Williamson, 1976), and at Dye-3 (Herron and others, 1985), GRIP (Thorsteinsson and others, 1997) and GISP2 in Greenland (Gow and others, 1997).

There are several mechanisms that could retard or completely inhibit grain growth, and the effect of each on $c$ - and a-axis orientation can be predicted. The first two involve the effects of impurities. First, second-phase particles can inhibit grain growth and grain-boundary migration (Gow and Williamson, 1976). It should be noted, however, that particle drag appears to reduce grain growth rates only in visibly 'dirty' ice, where particulate content is sufficiently high to be visible to the naked eye (i.e. ash bands); it appears to have little effect on grain growth in typical clean glacier ice (Alley and others, 1986). Second, soluble impurities in the grain boundaries can limit grain growth (Wolff and Paren, 1984; Budd and Jacka, 1989). Alley and others (1986) argue that the slowed grain growth and, hence, small grain size in GISP2 ice of the Wisconsin period is due to impurity drag, resulting from the high concentrations of $\mathrm{Na}^{+}$and $\mathrm{Cl}^{-}$. Concentrations of these ions, as well as $\mathrm{Ca}^{+}$and $\mathrm{NO}_{3}{ }^{-}$, are notably higher during the Younger Dryas $(1678 \mathrm{~m})$ and the Wisconsin period (starting at $1700 \mathrm{~m}$ ) (Yang and others, 1995; Gow and others, 1997; Mayewski and others, 1997; NSIDC, 1997). Because they are generally orientationindependent, these grain growth limiting effects would preserve the original fabric.

The next two possibilities involve the effect that new, smaller grains have on the average grain size. New, dislocation-free grains grow at the expense of the larger, highly strained grains. Nucleation and growth of strain-free grains and strain-induced boundary migration, also called migration recrystallization, is often found near the bottom of cores, where it is favored by the high strain energy and temperatures equal to or greater than $-10^{\circ} \mathrm{C}$ (Matsuda and Wakahama, 1978; Alley, 1988). Examples of this mechanism are found in the deepest $100 \mathrm{~m}$ of the Byrd ice core (Duval and Castelnau, 1995), in GRIP (Greenland Icecore Project; Thorsteinsson and others, 1997) and in GISP2 (Greenland Ice Sheet Project 2) below $3000 \mathrm{~m}$ (Gow and others, 1997). The fabric resulting from migration recrystallization probably depends on that of the preceding (shallower) ice as well as on the local state of stress. In laboratory ice, migration recrystallization has been shown to result in both ring and multi-maxima fabrics (Budd and Jacka, 1989). Below $3000 \mathrm{~m}$ in GISP2, a core characterized by a single-maximum fabric, migration recrystallization results in a ring-like distribution of $c$ axes (Gow and others, 1997). At Byrd, also characterized by a single maximum in $c$-axis orientations, it yields three or four tight clusters of $c$ axes distributed $45^{\circ}$ or $135^{\circ}$ apart from one another around the coring direction (Matsuda and Wakahama, 1978).

Finally, the process of polygonization, also called rotation recrystallization, may explain the lack of an increase in grain size despite increasing depth and age (Castelnau and others, 1996; Alley and others, 1997; Gow and others, 1997). Plastic deformation in natural, hexagonal ice $\left(I_{h}\right)$ is predominantly through shear on the basal plane, via glide of screw or $60^{\circ}$ dislocations on the $(0001)\langle 11 \overline{2} 0\rangle$ slip systems (Azuma and Higashi, 1985). Although edge dislocations can glide on the 
prismatic $\{10 \overline{1} 0\}$ and pyramidal $\{10 \overline{1} \overline{1}\}$ planes, the critical resolved shear stress for these are high compared to basal slip (Duval and Castelnau, 1995; Hondoh, 2000). A full discussion of the slip systems in ice can be found in Hondoh (2000).

The anisotropic plasticity and development of strong fabrics in polycrystalline glacial ice, where grains are constrained by their neighbors, has been attributed to the lattice rotations resulting from basal slip, where the $c$ axis rotates towards the compression axis and away from the direction of tension (Azuma and Higashi, 1985). Strain incompatibilities between adjacent grains can be accommodated by diffusion of point defects, the generation of geometrically necessary dislocations and grain-boundary sliding (Duval and others, 1983; Alley, 1988; Hondoh, 2000). Grain boundaries play an important part in all three mechanisms. Sliding between grains produces stress concentrations that generate dislocations, and grain boundaries also act as sinks for point defects (vacancies and interstitials) and dislocations. When slip is transmitted from one grain to another, the strain incompatibilities are accommodated by the generation of new dislocations, either on the grain boundary or in the grains. Further strain once a strong preferred fabric has developed, plus a small amount of thermal energy, leads to a reduction in dislocation density in grain interiors due to the coalescence of dislocations into lower-energy planes separating subgrains (Hondoh, 2000). This is the origin of polygonization.

The misorientation between the two areas on either side of the subgrain boundary is affected by the number and arrangement of dislocations. A continuously bent crystal has gradations in color when observed between crossed polarizers. As dislocations gather, subgrain boundaries form, producing areas differing in orientation by only a few degrees. These areas become more distinct as the misorientation between the subgrains increases. When the subgrains thus formed are counted as separate grains, the average grain size decreases.

This phenomenon has been identified in several welldocumented cores. In the Byrd core, Alley and others (1995) identify polygonization under increasing cumulative strain as the cause of regime 2, a region of constant grain size between 400 and $1200 \mathrm{~m}$. Separately, Thorsteinsson and others (1997) identified a region of decreased grain growth below $470 \mathrm{~m}$ in the GRIP core and, using statistical parameters, showed that the single-maximum $c$-axis fabric strengthens initially quite rapidly (from $249-470 \mathrm{~m}$ ), but then only gradually in the remainder of the Holocene ice, coincident with the decrease in grain growth. The slowing fabric and texture development below $650 \mathrm{~m}$ in GRIP has been attributed to polygonization (Castelnau and others, 1996).

Similarly, the characteristic fabric in the upper part of the GISP2 core is a single maximum that develops through the progressive reorientation of $c$ axes toward the vertical with increasing depth, caused by vertical compression combined with biaxial horizontal extension (Alley, 1988; Alley and others, 1997; Gow and others, 1997). Here, four regimes of crystal growth have been identified, with the first, described as linearly increasing grain size with increasing age, extending from the depth at which pore close-off occurs to approximately $750 \mathrm{~m}$ (Gow and others, 1997). Based on their data, and using the GISP2 Meese/Sowers timescale to plot grain area vs age, then adding a linear fit, the expected average grain size at $1500 \mathrm{~m}$ would be nearly $7 \mathrm{~mm}$ (Bender and others, 1994; Meese and others, 1994, 1997; NSIDC,
1997). However, the data show that grain size remains in the 3-4 mm range until the Younger Dryas event at $1678 \mathrm{~m}$ (Gow and others, 1997). Again, the reduction in grain growth is attributed to polygonization.

The existence of polygonization in both minerals and ice has been supported in part by the observation of clusters of grains with similar orientation on $\{0001\}$ pole figures (Alley, 1988; Lloyd and Freeman, 1994; Alley and others, 1995). However, Lloyd and others (1997) suggest that knowing the orientation of the boundaries in core ice is necessary to distinguish between polygonization, also called rotation recrystallization, and recrystallization involving nucleation and growth, and complete orientation information is necessary to fully describe the relationship between adjacent grains and to identify active slip systems.

Different recrystallization mechanisms will produce different $c$ - and a-axis fabrics. Migration recrystallization produces ring-like distributions or multi-maxima in pole figures. Polygonization may cause a widening of an existing $c$-axis fabric (e.g. a single maximum) (De La Chapelle and others, 1998) and, because individual larger grains split into two or more smaller grains of similar orientation, small clusters of poles on both $c$ - and a-axis pole figures may also be seen. Interestingly, either mechanism can produce clusters and, beyond recognizing the relationship of migration recrystallization to temperature, an examination of nearest-neighbor misorientation is useful for distinguishing between them.

There are a number of methods for determining orientations in polycrystalline ice. One of the simplest involves the formation of etch pits on the surface of the sample, the shape and orientation of which can be used to determine the orientation of each grain. Matsuda and Wakahama used this technique to examine the crystallographic structure of polycrystalline ice from different origins (i.e. laboratory, Antarctica and Alaska). As they obtained a-axis as well as $c$-axis directions, they were able to calculate misorientation axes and angles between adjacent grains and investigate the cause of multi-maxima fabrics (Matsuda and Wakahama, 1978; Matsuda, 1979). Although the etch-pit technique is useful in that it provides full spatial orientation, it is timeconsuming, requires skill and patience and is difficult to apply to grains only 1 or $2 \mathrm{~mm}$ across. More importantly, it provides only $5^{\circ}$ accuracy, and is thus of limited use in fully studying a mechanism involving very small misorientations (e.g. polygonization).

A comprehensive overview of other techniques, along with the theory behind them and comparison of their differences, can be found in Wilen and others (2003). In skilled hands, the commonly used manual optical technique utilizing thin sections, crossed polarizers and a Rigsby universal stage gives $c$-axis orientations accurate to $5^{\circ}$ (Langway, 1958). This technique has been automated in recent years by groups in Japan, Australia and the USA (Wang and Azuma, 1999; Wilen, 2000; Russell-Head and Wilson, 2001; Hansen and Wilen, 2002) making it more efficient and accurate. The US instrument's accuracy has been determined to be within $1^{\circ}$, based on statistical analysis of multiple runs. The accuracy of automated fabric analyzers based on optical methods is sufficient that they have been used to study changes in $c$-axis orientation caused by recrystallization. Hansen and Wilen (2002) demonstrated this technique by measuring the $c$-axis orientation of 22 points along a line within a single grain. Repeated runs 
a

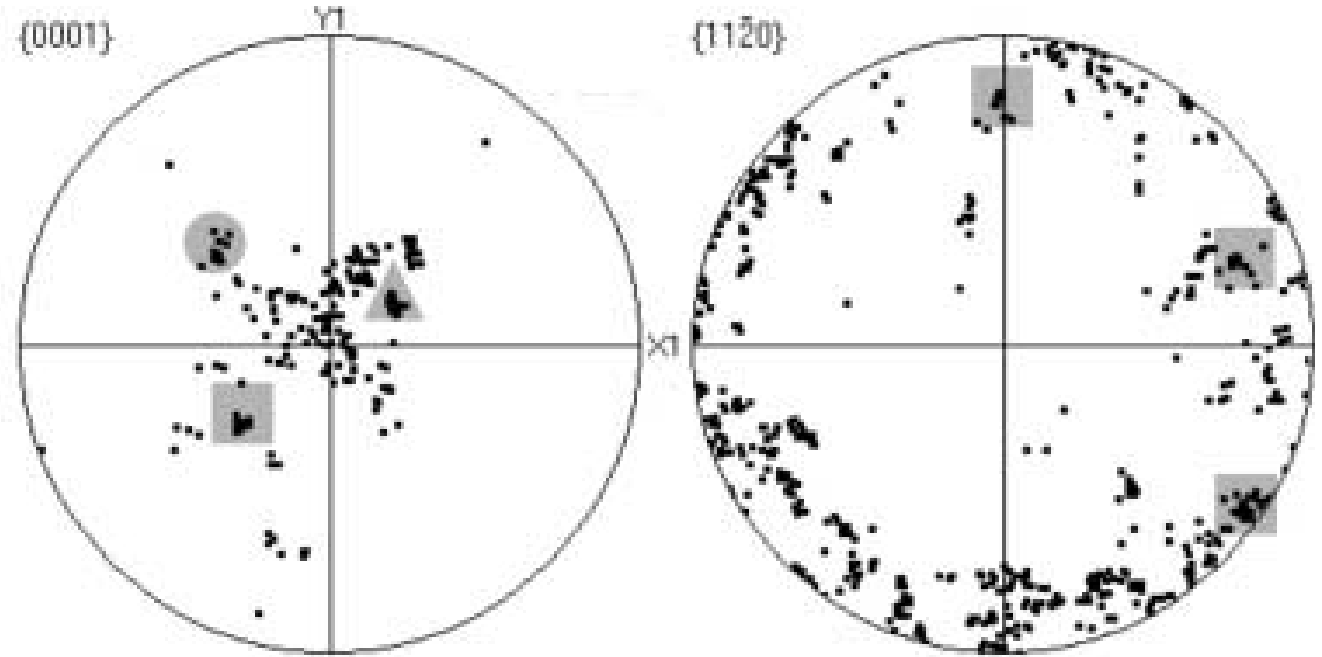

b

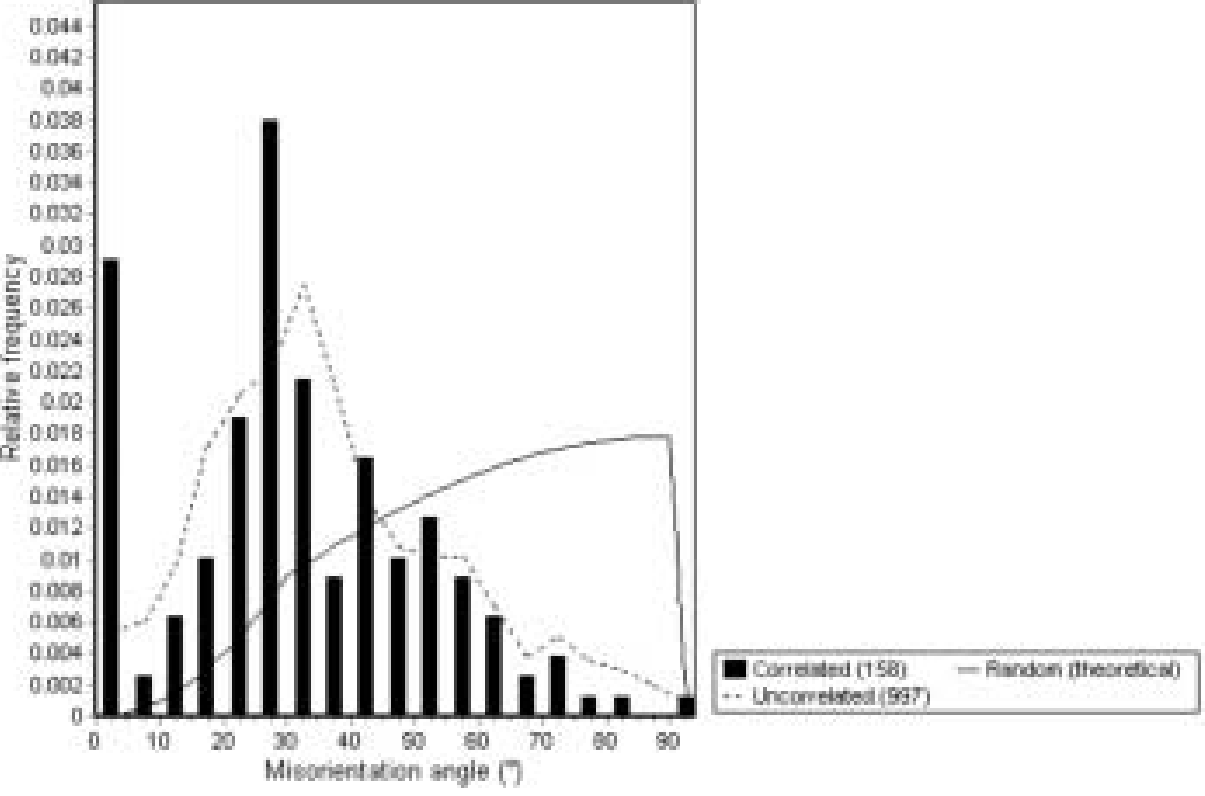

Fig. 1. GISP2 $1551.88 \mathrm{~m}$. (a) Pole figures (192 grains); and (b) misorientation-angle distribution (158 pairs of adjacent grains, 997 pairs randomly selected by the software). Shaded shapes on the pole figures are the clusters discussed in the text.

over the same set of points produced the same pattern on a pole figure, wherein the points varied by $6^{\circ}$ in polar angle and $12^{\circ}$ in azimuthal angle, although not in any easily explainable pattern.

Automated ice-fabric analyzers have been used in the study of nearest-neighbor relations by each group. Wilson and others (2003) used their instrument to study the changes in orientation caused by deformation, such as that found in shear zones. They found an asymmetric two-maxima fabric in the center of the shear zones, suggesting dynamic recrystallization, and distinct sets of nearest-neighbor misorientations at certain angular ranges. These preferred misorientation ranges suggested special grain-boundary relationships, but none were small enough to suggest subgrain rotation or polygonization. Azuma and others (2000) used their automated ice-fabric analyzer to study nearest-neighbor relations in samples from 0 to $2500 \mathrm{~m}$ in the Dome Fuji (Antarctic) ice core and found, between 1300 and $2000 \mathrm{~m}$, significantly more low-angle misorientations between adjacent grains than between randomly chosen grain pairs, suggesting that polygonization had taken place in this region. Wilen and others (2003) performed a similar analysis on GISP2 ice and found a correlation in $c$-axis orientation between nearest neighbors in the $0-1500 \mathrm{~m}$ depth range, but the strength of this correlation varied. Since the $c$-axis direction is only one component of orientation, it is conceivable that there is more to the nearest-neighbor relations than can be revealed with this information alone. Knowing the directions of a axes of adjacent grains is also necessary to fully understand their relationship. Hence, it seems that optical methods based on identifying the optic (or c) axis are insufficient for analyzing nearest-neighbor relations.

Finally, x-ray diffraction has been used to determine orientations in ice (e.g. Mori and others, 1985) and while this technique provides both $c$ - and a-axis orientations, it is slow due to the weak diffraction of x-rays by ice.

Recently, we developed an electron backscatter diffraction (EBSD) method to measure orientation in polycrystalline ice (Iliescu and others, 2004), which can be used to determine the full ( $c$ - and a-axis) misorientation between adjacent grains. In this paper we apply this method in an examination of nearest-neighbor relationships in three sections of the GISP2 core to confirm the presence and investigate the nature of polygonization. 

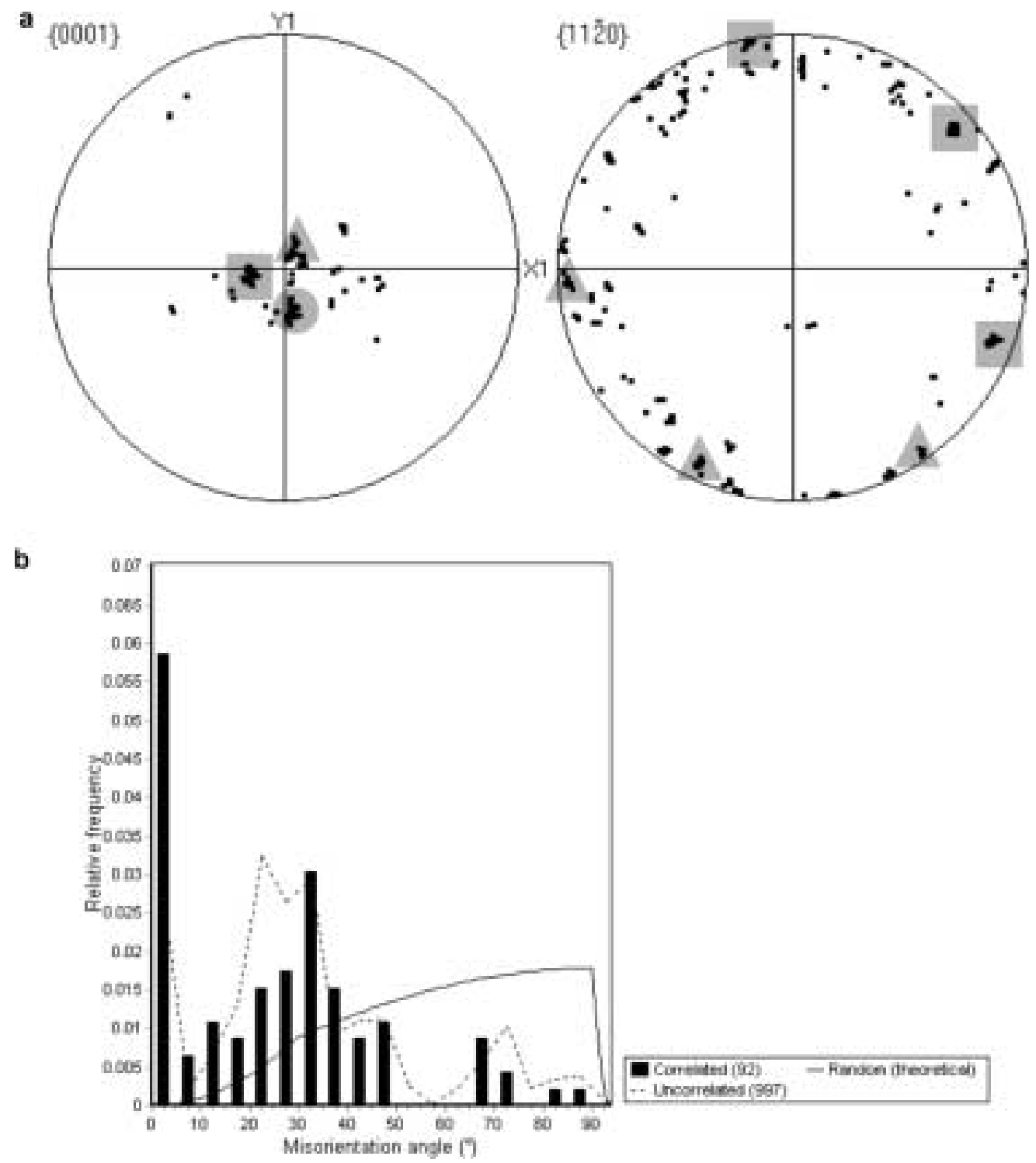

Fig. 2. GISP2 $1642.03 \mathrm{~m}$. (a) Pole figures (110 grains); and (b) misorientation-angle distribution (92 adjacent grain pairs, 997 random pairs). Shaded shapes on the pole figures are the clusters discussed in the text.

\section{METHODS}

Three GISP2 core specimens were examined, from depths of 1551.85-1551.88, 1642.03-1642.06 and 1745.035$1745.065 \mathrm{~m}$. These were obtained from the US National Ice Core Laboratory in Denver, CO. They were stored there at $-35^{\circ} \mathrm{C}$, and then in the Ice Research Laboratory at the Thayer School of Engineering at Dartmouth College at $-25^{\circ} \mathrm{C}$. Sample preparation took place in $\mathrm{a}-15^{\circ} \mathrm{C}$ cold room.

Samples approximately $3 \times 1.5 \times 0.3 \mathrm{~cm}$ were cut horizontally (perpendicular to the core axis) from each specimen. Multiple samples from a single specimen were cut with the same orientation (i.e. with their long axes parallel) so their EBSD orientation data could be plotted on the same pole figures.

For the grain-boundary mapping used in nearest-neighbor analysis, one piece was taken from either side of a single cut made with a $\sim 1 \mathrm{~mm}$ bandsaw blade. The formerly adjacent surfaces were smoothed by shaving them with a razor blade, removing as little material as possible so that the location of grain boundaries corresponded well between the two pieces. The formerly adjacent side of the first piece was mounted on a glass plate, and a thin section approximately $3 \times 1.5 \mathrm{~cm}$ was prepared and photographed between crossed polarizers using a digital camera. The thin section was rotated between the polarizing sheets and multiple images were captured, so that all variations in lattice orientation visually detectable by variations in color and shade were recorded. These images were used to locate grain boundaries on the second piece in a scanning electron microscope (SEM) using EBSD.

The EBSD samples were frozen, formerly adjacent side up for those mapped, to a brass sled that was then mounted on $\mathrm{a}-65^{\circ} \mathrm{C}$ cold stage in an FEI XL-30 environmental SEM. The SEM operated at $15 \mathrm{kV}$ with a $0.15 \mathrm{nA}$ beam current, and the ice was examined at temperatures between -40 and $-65^{\circ} \mathrm{C}$ at a pressure of $\sim 5 \times 10^{-4} \mathrm{~Pa}$. EBSD patterns were captured using the techniques described by Iliescu and others (2004). Grain boundaries and triple junctions were identified on the specimen visually, using the SEM imaging capabilities. Grain boundaries were identified by (a) a clear grain-boundary groove and/or (b) a change in the surface etching pattern, the pattern of white spots on a black background that varies with lattice orientation (Obbard and others, 2006). For the 
a

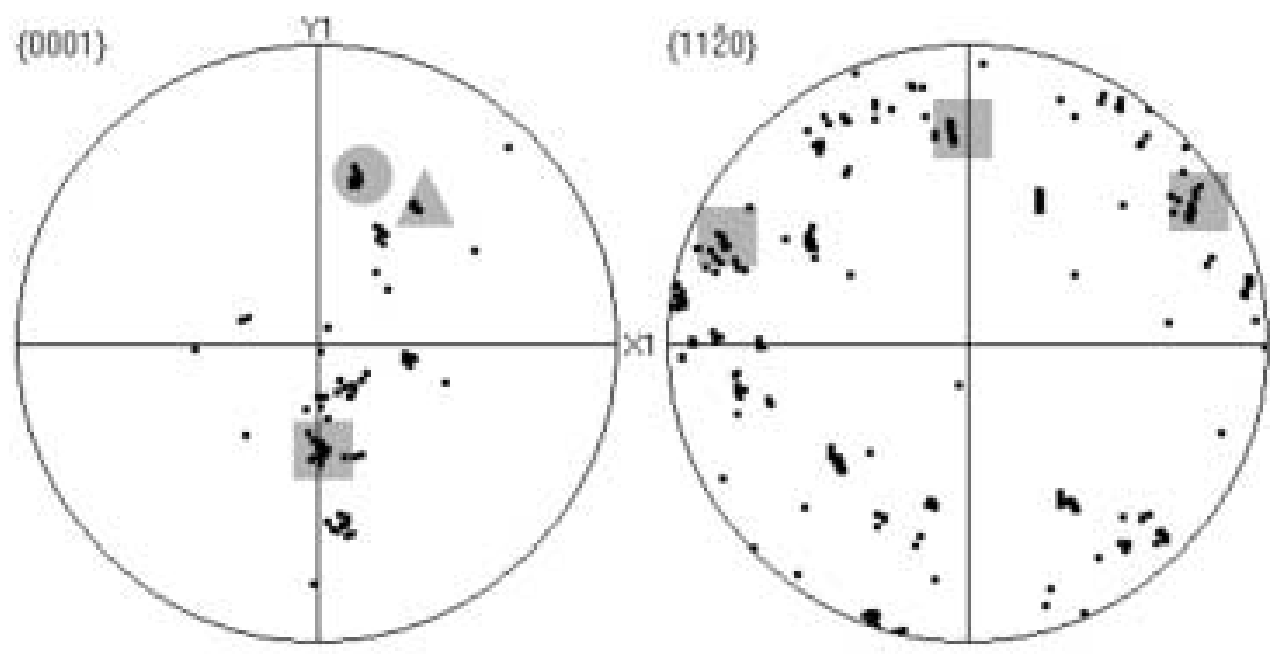

b

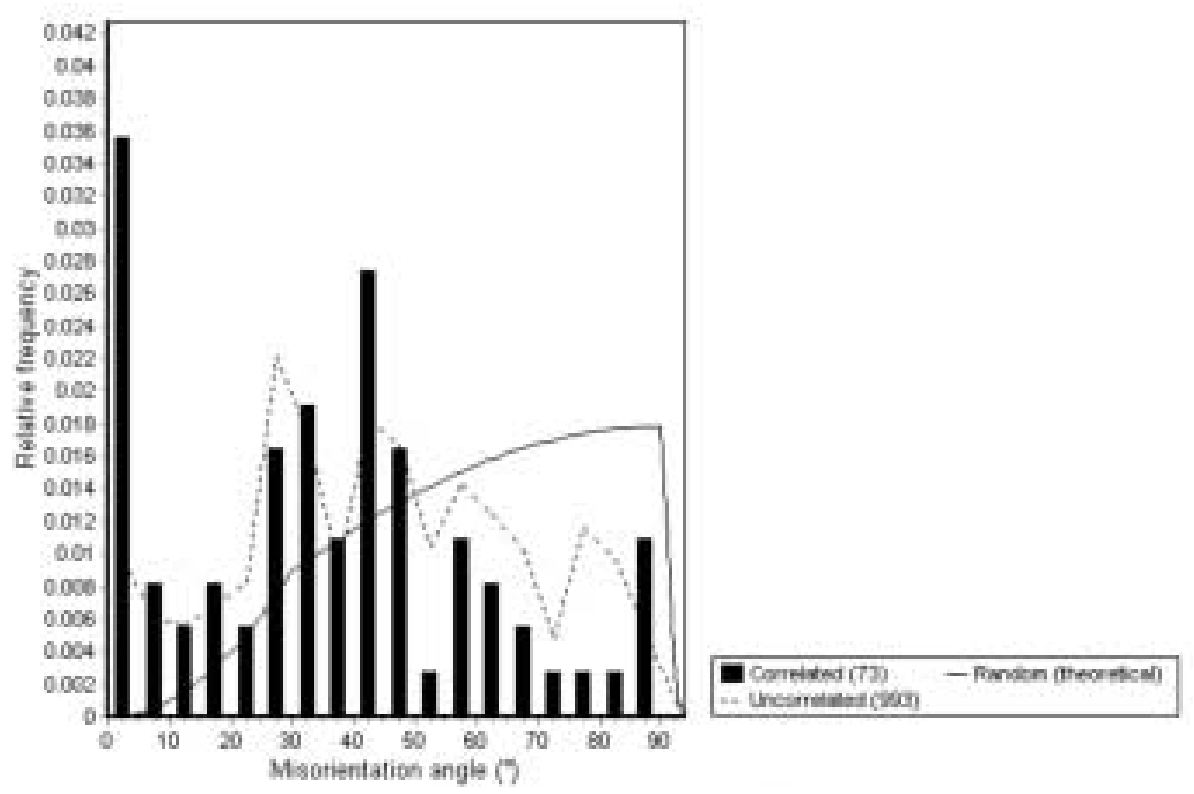

Fig. 3. GISP2 $1745.035 \mathrm{~m}$. (a) Pole figures (90 grains); and (b) misorientation-angle distribution (73 adjacent grain pairs, 993 random pairs). Shaded shapes on the pole figures are the clusters discussed in the text.

mapped samples, differences in orientation not marked by visible boundaries but expected from the thin-section images taken previously were detected by collecting a diffraction pattern every $200 \mu \mathrm{m}$ and looking for variations in orientation that were greater than that caused by change in beam-sample geometry. Based on prior measurements, the implied change in specimen orientation due to moving the beam across the specimen is $1.07^{\circ}$ per $2 \mathrm{~mm}$ traverse on the specimen, which is consistent with the typical $\sim 1^{\circ}$ 'orientation noise' reported by Bate and others (2005). The distance between measurements across grain boundaries was typically $\sim 100 \mu \mathrm{m}$. Hence, misorientations between adjacent grains were measurable to an accuracy of $0.1^{\circ}$. Differences in orientation between two locations that were greater than that caused by moving the beam laterally across the surface were considered significant, and a representative pattern was captured from each such area and correlated with its location on the thin-section image. For the samples not having corresponding thin sections and grain-boundary maps, subgrain boundaries not visible in the SEM image may have been missed. Thus, the pole figures may underrepresent clustering.
The EBSD patterns were indexed using HKL Technology's CHANNEL $5^{\text {(ix }}$ software, and the misorientation between grains was calculated according to the method of Randle and Engler (2000). Misorientation is described by a common axis and the angle by which one grain must be rotated around this axis to achieve lattice coincidence with the other. In the hexagonal crystal system, there are 12 possible angle-axis pairs (Kasper and Lonsdale, 1959) but in this discussion we define the smallest of the 12 angles as the misorientation angle. The misorientation angles are presented as a histogram (in Figs $1 \mathrm{~b}, 2 \mathrm{~b}$ and $3 \mathrm{~b}$ ) which compares the distribution of rotations between adjacent grains (correlated data, shown with bars) with the distribution of misorientation angles between random pairs of grains in the dataset (uncorrelated data, dashed line) and the theoretical distribution curve for a system of hexagonal grains (solid line), calculated by the software based on the work of Mackenzie (1958) and Morawiec (1995). The calculated misorientations are binned into $5^{\circ}$ groups. We divided the $x$ axis into bins that each include $5^{\circ}$ of misorientation, because using narrower bins left many unfilled. In this histogram, produced by HKL software, the $y$-axis scale takes bin width into account. If the 

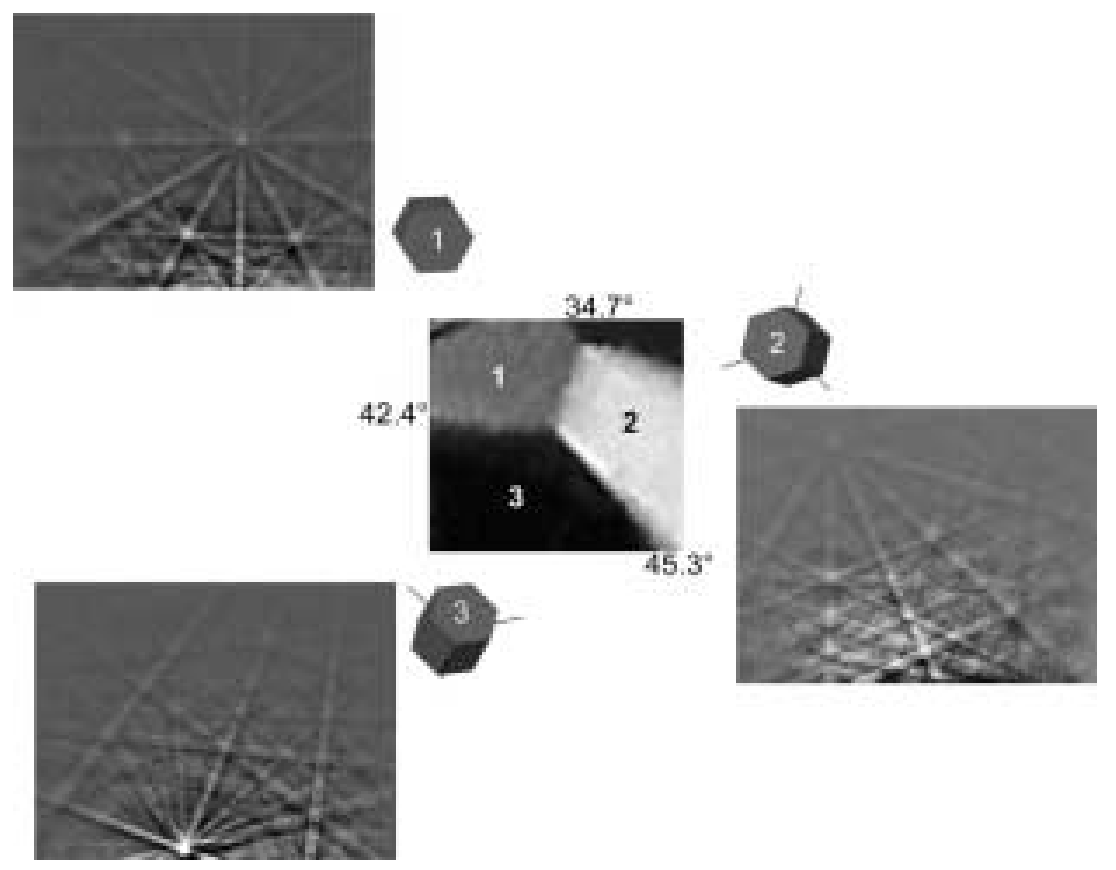

Fig. 4. At center, part of a GISP2 $1745 \mathrm{~m}$ thin section showing a triple junction (image $\sim 3 \mathrm{~mm}$ across). The grain boundaries are labeled with their misorientation angles. Around this image are the diffraction patterns obtained from the grains, and schematics showing crystal orientation.

bins were $1^{\circ}$ wide, their combined heights, where height is relative frequency, would add up to 1.0 . Since each bar contains misorientation angles within a range of $5^{\circ}$, its height must be multiplied by 5 for the sum of the bars to add to 1.0 .
An uncorrelated distribution that differs from the theoretical distribution indicates a preferred orientation (or fabric) overall in the material, which would also be observed on the pole figures. A distribution of correlated misorientations that

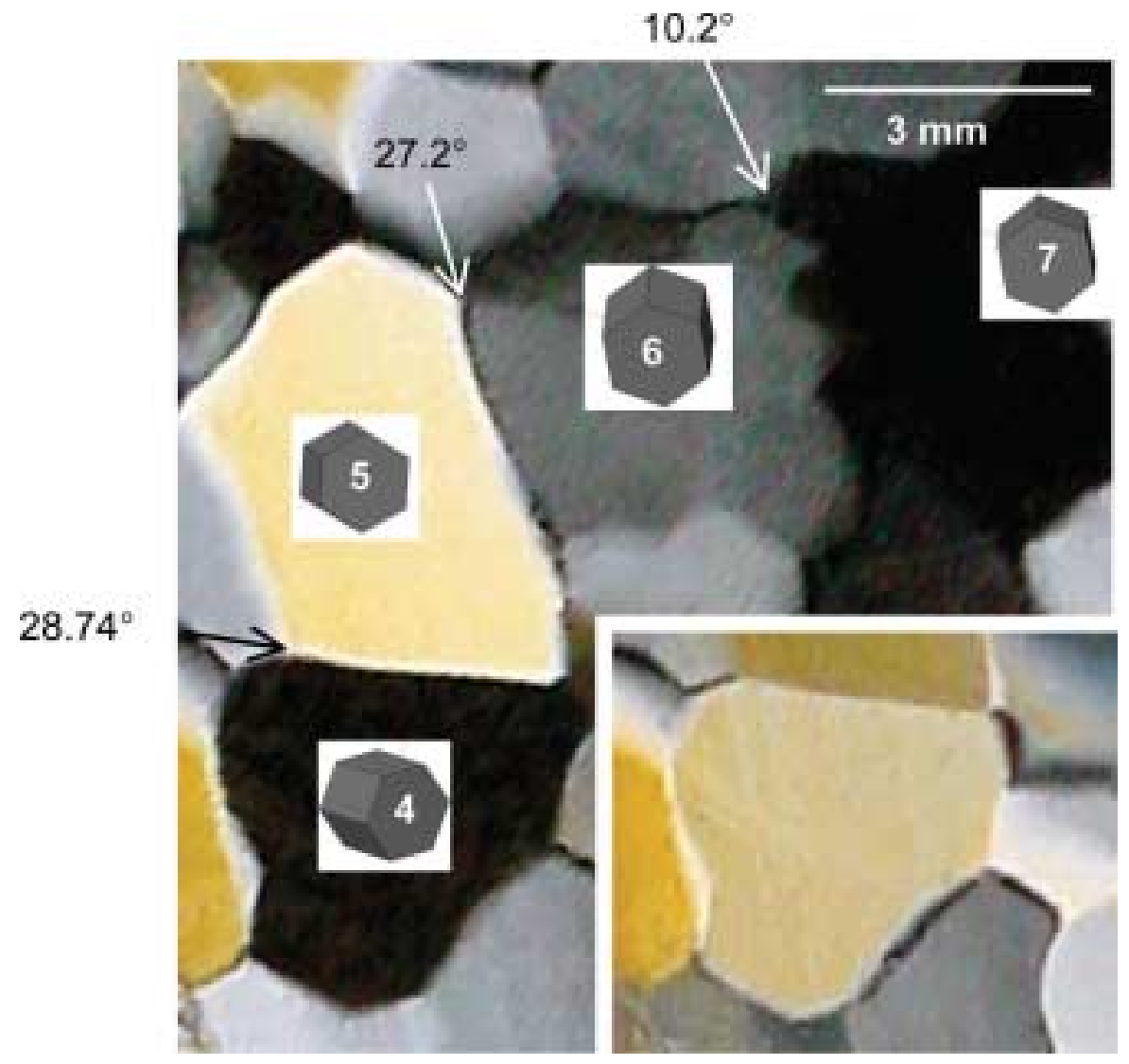

Fig. 5. Thin section from GISP2 $1745 \mathrm{~m}$ with schematics showing the orientation of certain crystals, and the misorientation angles across shared grain boundaries. Inset shows how grain colors change as crossed polarizers are rotated. 


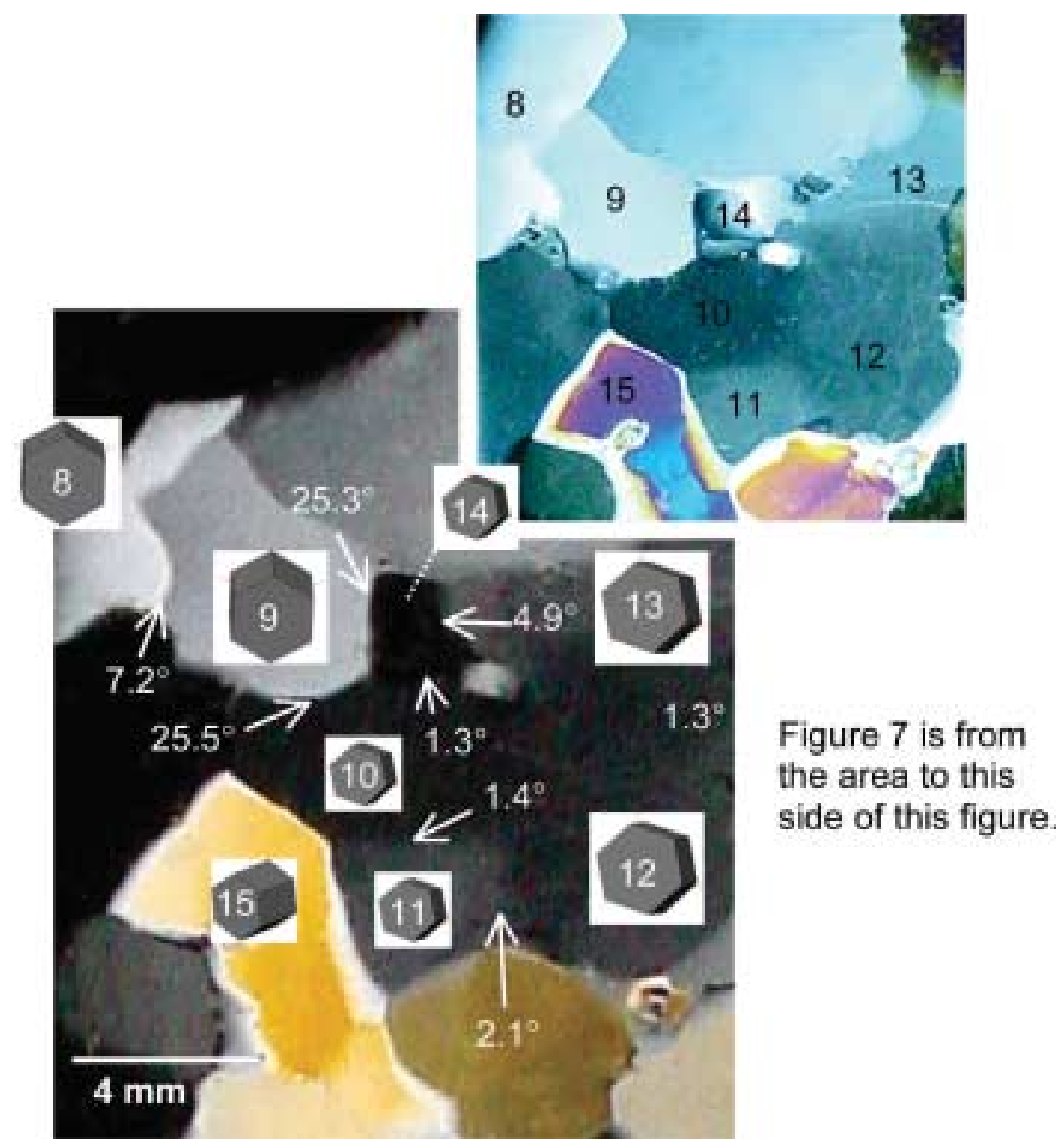

Fig. 6. Thin section from GISP2 $1642 \mathrm{~m}$ with schematics showing the orientation of certain crystals, and the misorientation angles across shared grain boundaries. Inset is thin section of the same area showing grains 10-13 more clearly.

differs from that of the uncorrelated misorientations, however, suggests a special relationship between adjacent grains such as that resulting from twinning or polygonization. The statistical significance of the differences between the nearestneighbor (correlated) misorientation-angle distribution and the uncorrelated misorientation-angle distribution of random pairs was determined using the Kolmogrov-Smirnov (K-S) test, described by Cheeney (1983) and recommended for this application by Wheeler and others (2001). This test is based on the maximum difference between the two cumulative frequency distribution functions $(D)$ and the sample sizes of correlated (adjacent pair) and uncorrelated (random pair) data, $N_{c}$ and $N_{u}$ :

$$
d=D \sqrt{\frac{\left(N_{\mathrm{c}} \times N_{\mathrm{u}}\right)}{\left(N_{\mathrm{c}}+N_{\mathrm{u}}\right)}} .
$$

The probability that the two populations are different is associated with the value of $d$, which is interpreted with the use of statistical tables where $d$ is 1.882-1.949 (depending on sample size) for a $99.9 \%$ probability (Lindley and Scott, 1995).

\section{RESULTS}

Fabric and misorientation-angle distribution histograms for each depth are shown in Figures 1-3. Note that each crystal supplies one pole on the $\{0001\}$ pole figure, but three, $60^{\circ}$ apart, on the $\{11 \overline{2} 0\}$ pole figure.

The $1551 \mathrm{~m}$ specimen has a weak single maximum in the $\{0001\}$ pole figure (Fig. 1a). On the $\{11 \overline{2} 0\}$ pole figure, a corresponding arrangement of poles is present, i.e. they lie around the outside of the pole figure, at $90^{\circ}$ to the $c$ axes of the same grains. As an example, the shaded squares on the $\{11 \overline{2} 0\}$ pole figure contain the $a$ axes for the grains whose $c$ axes are in the shaded square on the $\{0001\}$ pole figure. There are several of these pole clusters on the $\{0001\}$ pole figure; a second and third are indicated with a shaded circle and triangle. Because diffraction data were tabulated with position on the sample, the location on the sample of each pole in the cluster can be identified. It was found that each cluster contains two types of poles. About half of the poles in a cluster are from adjacent grains in the sample. The other half are from grains whose nearest neighbors have poles in another cluster. In other words, adjacent grains have $c$ axes in two different clusters and, as diffraction patterns are collected across these areas on the sample, the $c$-axis pole alternates between the two clusters. For example, note the clusters within the shaded square and triangle in Figure 2 $(1642 \mathrm{~m})$. Four grains which lie in a line across the surface of the sample, and which we labeled 60-63 in our data, fall in these two clusters such that the pole for 60 is in the square, the pole for 61 is in the triangle, the pole for 62 is in the 
square and the pole for 63 is in the triangle. The corresponding poles on the $\{11 \overline{2} 0\}$ pole figure are grouped in the same manner, falling alternately in the clusters marked with squares and triangles. Sometimes adjacent grains have poles in the same clusters and other times the adjacent grains' poles fall into two different orientations.

The misorientation-angle distribution for the $1551 \mathrm{~m}$ specimen is shown in Figure 1b. These data were collected from just one of the samples from this specimen, hence the small number of adjacent grain (correlated) data compared to the number of poles on the pole figure. The highest misorientation angle found in this study was $91.9^{\circ}$, within the maximum misorientation for hexagonal ice of $104.5^{\circ}$ (Mackenzie, 1958; Wheeler and others, 2001). Because of the strong single-maximum fabric, the misorientation-angle distribution differs significantly from the Mackenzie (theoretical) distribution for a hexagonal polycrystal, as would be expected. The distribution of random-pair misorientations (uncorrelated data) has a maximum at $30-35^{\circ}$. A perfect single-maximum fabric, with all $c$ axes oriented identically, but with no correlation in a-axis orientation, would yield misorientations of only $1-30^{\circ}$, since $30^{\circ}$ is the maximum unique rotation about the $c$ axis. Thus, variation in $c$-axis orientation, as seen on the $\{0001\}$ pole figure, is required to obtain misorientation angles greater than $30^{\circ}$. The primary differences between the correlated and uncorrelated distributions are the large number of very-low-angle $\left(1-5^{\circ}\right)$ misorientations and $25-30^{\circ}$ misorientations between adjacent grains (correlated data). Based on the K-S test, the probability that the former is statistically significant is greater than $95 \%$. Hence, there is a correlation between nearestneighbor grains and low-angle misorientations.

The $1642 \mathrm{~m}$ specimen produced a tighter single maximum in the $\{0001\}$ pole figure, again with clusters (Fig. 2a) associated with neighboring grains. Each cluster contains 15-44 poles, including several groups of 3-10 poles, each from adjacent grains (or subgrains). Again, there is a relationship between adjacent grains where their poles alternate between two clusters. On the $\{11 \overline{2} 0\}$ pole figure, a corresponding arrangement of poles is present, and an example of the corresponding a-axes clusters for two $c$-axis clusters (shaded square and shaded triangle) is shown. In the misorientation-angle histogram (Fig. 2b), the correlated and uncorrelated distributions are very similar, with the exception of a far greater proportion of very-low-angle $\left(1-5^{\circ}\right)$ misorientations between adjacent grain pairs. Based on the $\mathrm{K}-\mathrm{S}$ test, the probability that this difference is statistically significant is greater than $99 \%$. Hence, as in the $1551 \mathrm{~m}$ sample, there is a correlation between nearest-neighbor grains and low-angle misorientation.

A similar situation, corresponding clustering of neighboring grains' poles on the $\{0001\}$ and $\{11 \overline{2} 0\}$ pole figures and low-angle misorientations between these adjacent grains, is present in the data from the $1745 \mathrm{~m}$ specimen, shown in Figure 3. In the misorientation-angle histogram (Fig. 3b), the correlated and uncorrelated distributions are very similar, with the exception of a far greater proportion of very-lowangle $\left(1-5^{\circ}\right)$ misorientations and a (statistically insignificant) greater proportion of $40-45^{\circ}$ misorientations between adjacent pairs. Based on the $\mathrm{K}-\mathrm{S}$ test, the probability that the greater number of $1-5^{\circ}$ misorientations in the adjacent pairs is statistically significant is greater than $97.5 \%$. Here too, then, adjacent grains are more likely to share very-lowangle $\left(1-5^{\circ}\right)$ boundaries.

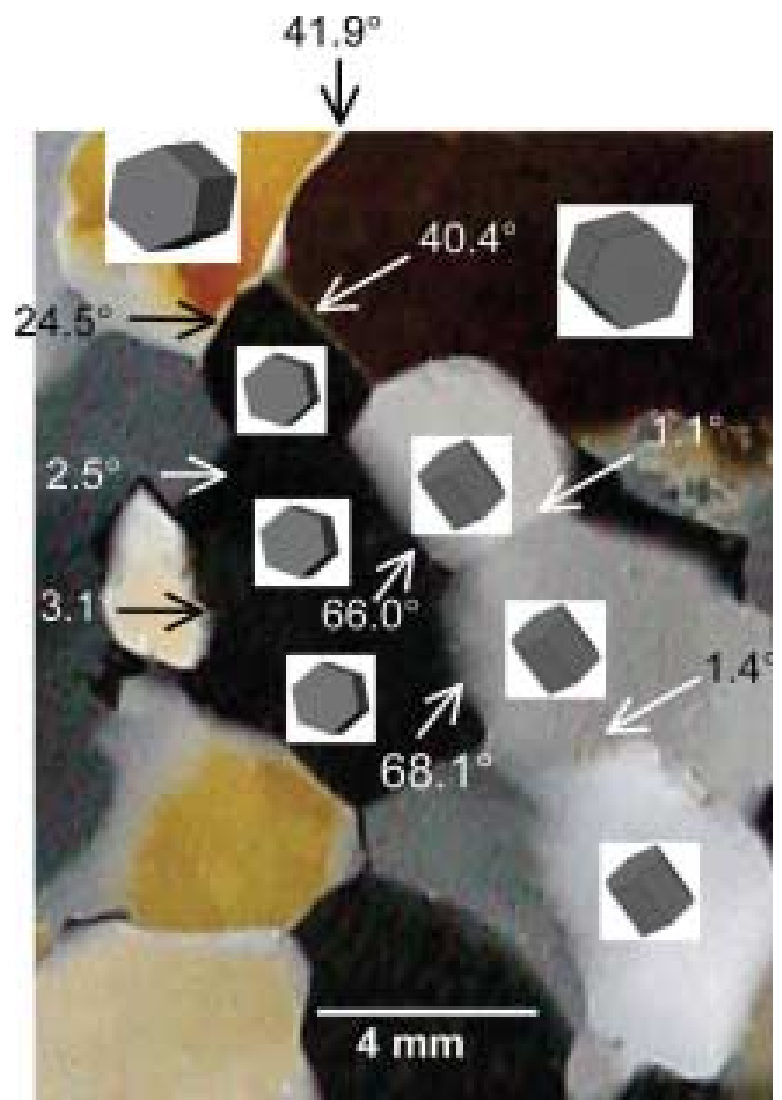

Fig. 7. Thin section from GISP2 $1642 \mathrm{~m}$ with schematics showing the orientation of certain crystals, and the misorientation angles across shared grain boundaries. There is a small overlap between the left of this figure and the right of Figure 6.

Some thin sections are shown in Figures 4-7. The associated three-dimensional (3-D) crystal representations are useful for visualizing the differences in orientation between nearest-neighbors and for comparing those differences to the appearance of the shared boundary. Figure 4 is an example of three adjacent grains (with quite different orientations) and their diffraction patterns. The 3-D crystal orientations obtained by indexing the patterns and the calculated misorientation angles are also shown. The orientations of grains 2 and 3 are related by a $45.3^{\circ}$ rotation about an a axis which lies on the grain boundary between them. Thus, it is not surprising that the grains appear very different in color and their boundaries are well defined. Although grain 3 appears almost black, it lightened considerably as the section was rotated between the polarizers, and hence it is not oriented with the $c$ axis normal to the surface of the sample.

A similar situation is shown in Figure 5, where the inset illustrates how grain color (of grain 4 in this instance) changes as a thin section is rotated between crossed polarizers. Figure 5 illustrates the misorientation angles that are associated with some of the different grain-boundary morphologies observed in thin sections. The misorientation angle between grains 4 and 5 is $28.7^{\circ}$, and the boundary between them is straight and well defined. The same is true of grains 5 and 6 , which differ in orientation by $27.2^{\circ}$. Grains 6 and 7 , however, differ by only $10.2^{\circ}$, attributable to differences in both $c$ - and a-axis orientation, and share an undulatory boundary. Undulatory boundaries are considered indicative of subgrains (I. Hamman and others, unpublished information). 


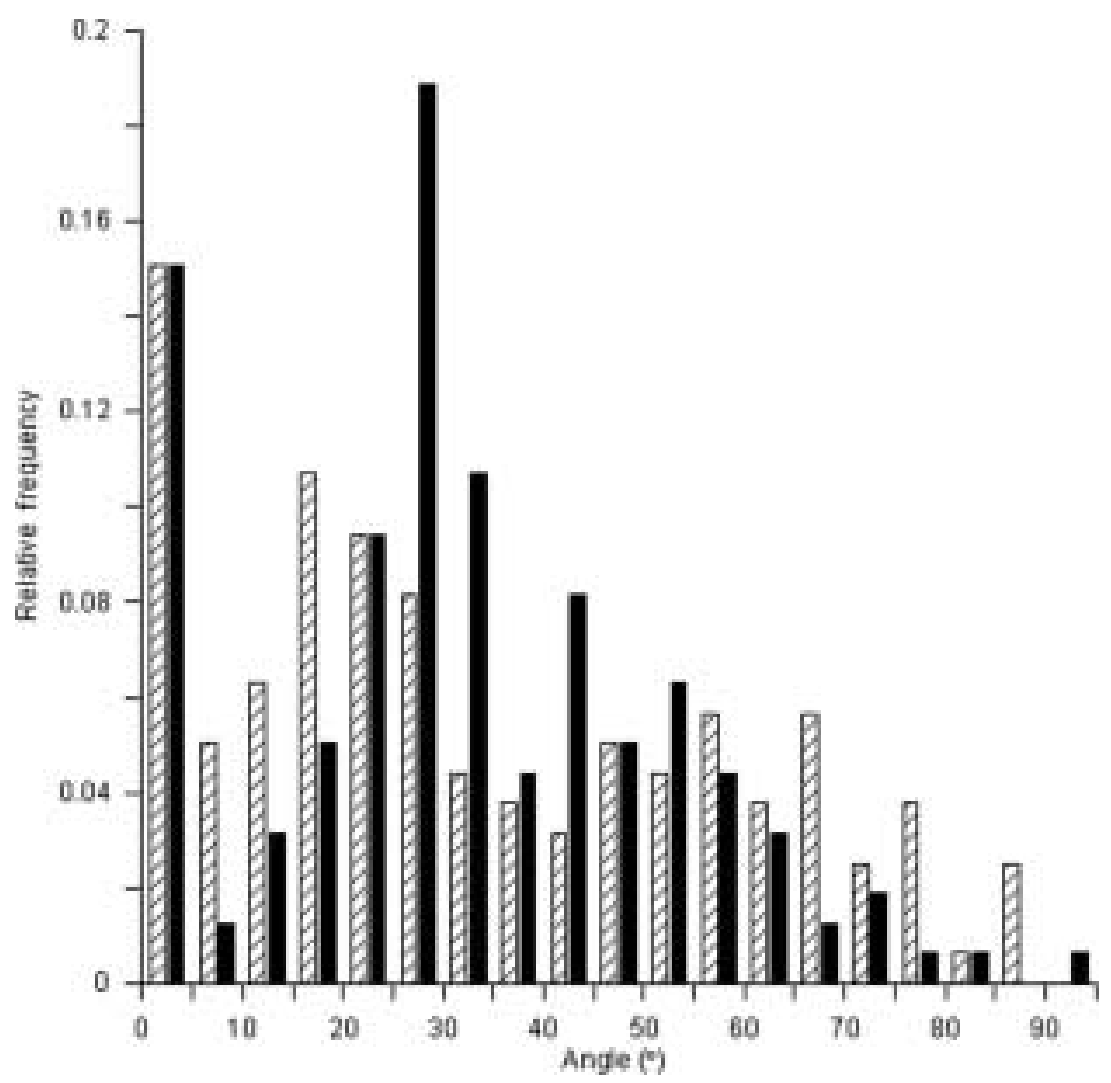

Fig. 8. GISP2 $1551.88 \mathrm{~m}$. Histogram comparing misorientation-angle distribution between adjacent grains (solid bars) with the distribution of angles between the $c$ axes (hatched bars) for the same grain pairs (158 pairs).

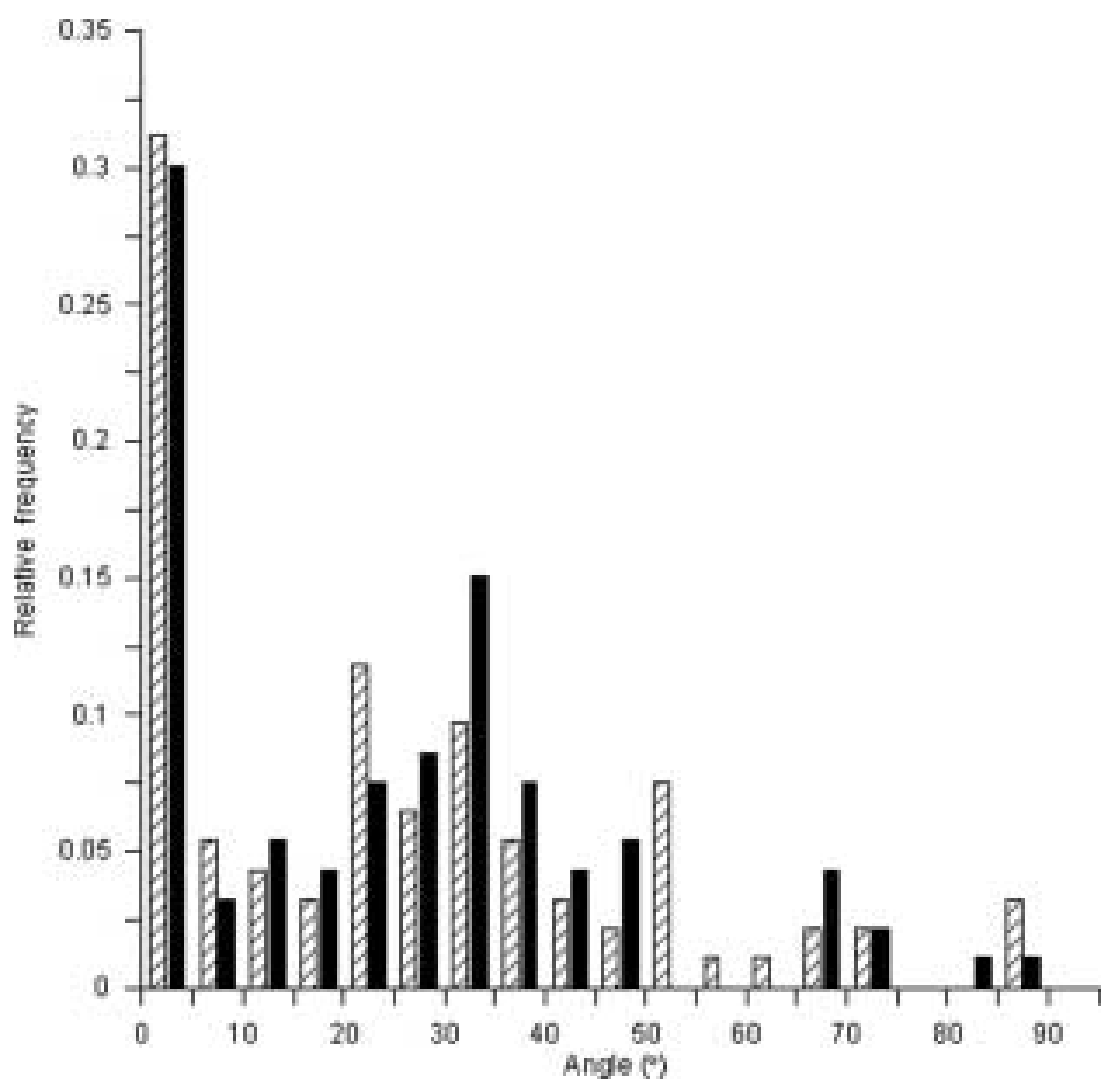

Fig. 9. GISP2 $1642.03 \mathrm{~m}$. Histogram comparing misorientation-angle distribution between adjacent grains (solid bars) with the distribution of angles between the $c$ axes (hatched bars) for the same grain pairs (92 pairs). 


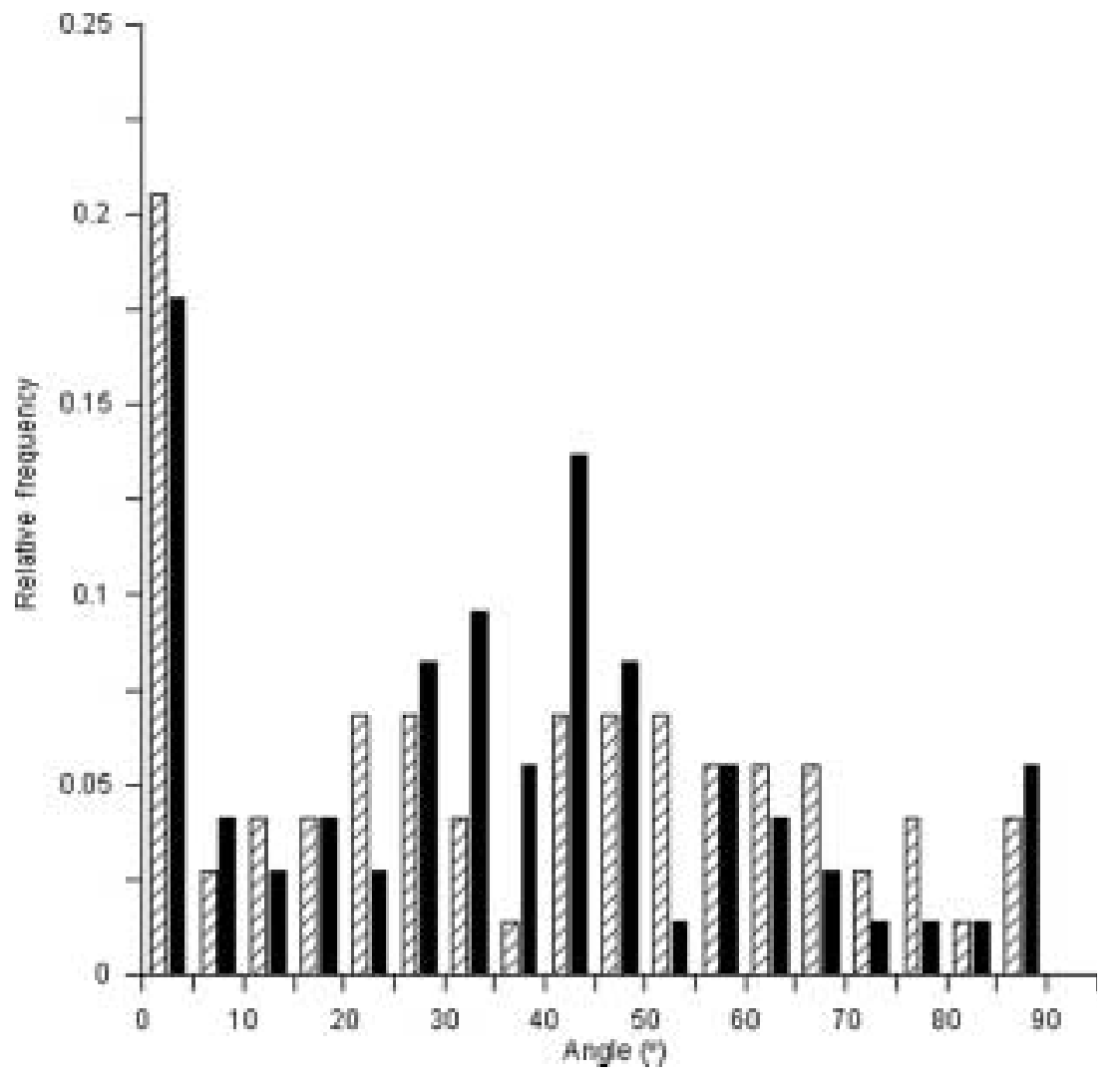

Fig. 10. GISP2 $1745.035 \mathrm{~m}$. Histogram comparing misorientation-angle distribution between adjacent grains (solid bars) with the distribution of angles between the $c$ axes (hatched bars) for the same grain pairs (73 pairs).

Another example of an undulatory grain boundary is shown in Figure 6, between grains 8 and 9, which differ in orientation by $7.2^{\circ}$. Note that in both these examples of undulatory boundaries, the trace of the undulations is approximately parallel to the trace of the prismatic planes.

Another type of boundary attributed to polygonization is where there is a gradual shift in shade between two grains (or subgrains), as between grains 10, 11 and 12 in Figure 6. Depending on orientation of the sample with the polarizing film, fine distinctions in shading between areas of differing orientation can easily be obscured. A series of images was made of this sample (by rotating the thin section between crossed polarizers) in which such differences are seen quite clearly, and one is included as an inset in the figure. The misorientation across these fading boundaries (e.g. grains 10 and 11,11 and 12 and 12 and 13) is only $1-2^{\circ}$ and coincidence can be achieved by a rotation about an a axis.

More examples of this type of low-angle boundary can be seen in Figure 7, which is from the same original photograph as Figure 6. Grains $10-13$ in Figure 6 are all so similarly oriented that they could easily be mistaken for a single grain, and in some images they appeared so. However, their differences in orientation, obtained from EBSD patterns, are consistent with the change in shade seen in most orientations (of thin section relative to polarizers). In contrast, the two apparent sets of subgrains in Figure 7 are quite differently oriented from one another, by about $66-68^{\circ}$. Interestingly, the rotation axes for the subdivision of a larger grain into three smaller ones appear to have taken place along the same direction in both groups, and referring back to Figure 6 , the same could be said of the pairs of grains numbered 10 and 11, and 12 and 13 .

\section{DISCUSSION}

A comparison of crystal orientation with location may help us to understand the relationships between polygonized subgrains and their appearance in thin sections. In this study, areas that were differentiated by a gradual change in shade on thin sections were found to be misoriented by $1-5^{\circ}$ and have $a$ axes lying in the same direction. Dislocations on the basal plane have screw and $60^{\circ}$ components. The low-angle rotations about the a axes may represent tilt boundaries associated with $60^{\circ}$ dislocations. Undulatory boundaries were associated with larger misorientations. The traces of their undulations were approximately parallel to the traces of the prismatic planes. Not enough boundaries of this type were studied to determine whether this is significant, but this observation may be worth further research. It is possible that it is evidence of polygonization stemming from $60^{\circ}$ dislocations and tilt boundaries in the $\langle 11 \overline{2} 0\rangle$ direction. Up to this time, observations of polygonization have been based on comparisons of $c$-axis orientation. Certainly, the addition of very accurate a-axis orientation will allow more to be learned about polygonization mechanisms. Examples of the differences between the two types of data can be seen in Figures 8-10. The HKL software provides only complete misorientation, which takes into account differences in $c$ - and a-axis direction. To find the angle between the $c$ axes of the same pairs of grains (correlated data), we measured the distance between the $\{0001\}$ poles with a Wulff net drawn to $2^{\circ}$ intervals. The accuracy of this method is only about $1^{\circ}$, but since the data are presented in histograms with $5^{\circ}$ bins, it is sufficient for this purpose. In Figures 8-10, the complete misorientation angles between the points included 
in Figures $1 \mathrm{~b}, 2 \mathrm{~b}$ and $3 \mathrm{~b}$ (solid bars) are compared to the angles between their $c$ axes only (hatched bars). Note that the $y$ axis here is relative frequency, unadjusted for bin width, where the sum of the bar heights equals one. In each figure, the greatest proportion of angles between $c$ axes is in the $1-5^{\circ}$ range, an indicator of the strong fabric in these samples.

Note that in Figures 8 and 9 , the $0-5^{\circ}$ bin bar heights are almost identical between the $c$-axis only data (hatched bar) and complete misorientation (solid bar). Based only on the $c$-axis data, we do not know for certain that the adjacent pairs supplying these points share low-angle boundaries (i.e. despite similarly oriented $c$ axes, their a axes could be up to $30^{\circ}$ different in direction). The fact that the complete misorientation data also peak in this angular range demonstrates that both the $c$ and $a$ axes are similarly oriented, as would be the case if these adjacent grains were related by a rotation about the a axis. This supports the idea that low-angle tilt boundaries have been formed.

Obviously, not all adjacent grains are related by polygonization. Those which are not could still share $c$-axis direction, due to the overall fabric in the ice, but may differ in a-axis direction. The $25-50^{\circ}$ range peaks in the complete misorientation data, which did not pass the K-S test for statistical significance, probably reflect these nearestneighbor orientations. Grains with identical $c$ axes could have total misorientations of up to 30; those with $c$ - and a-axis differences would produce other misorientations.

On the $\{0001\}$ pole figures, we see clusters resembling those in a multi-maxima fabric (Gow and Williamson, 1976). The multi-maxima fabric is generally associated with migration recrystallization, and its appearance has been explained as resulting from repeated sampling of a few large, interconnecting or network-like ice crystals as they intersect the plane of the thin section (Matsuda and Wakahama, 1978). Migration recrystallization is unlikely to be the cause of the clusters seen in the samples examined in this paper for several reasons. First, this recrystallization mechanism is generally observed near the base of a glacier, where temperatures are warmer than $-10^{\circ} \mathrm{C}$ (Alley, 1988). The depths we tested, 1551-1745 m, are from the upper twothirds of the GISP2 core, where the temperature is around $-32^{\circ} \mathrm{C}$ (NSIDC, 1997). Second, as shown in Figures $5-7$, and as observed by others (Gow and others, 1997), the grain size at these depths is actually quite small, not large as in the case of migration recrystallization. Third, and most importantly, the repeated intersection of a single large, interconnected grain by a thin section would produce no pattern in the location of the similarly oriented 'grains' on the thin section. The correlation of adjacent areas and their poles described in the preceding section would not be observed. Instead of appearing in groups or lines, 'grains' of similar orientation would probably be distributed randomly across the surface. Further, there would not be any correlation between their location and their shared boundary such as that seen in Figures 6 and 7, where we see parallel groups of polygonized grains. Hence it is unlikely that migration recrystallization is the cause of the clusters in Figures 1-3. Finally, we recognize that in some previously published work, clusters are not seen in the $\{0001\}$ pole figures for GISP2 ice from this depth range (Gow and others, 1997). Those data were obtained using the Rigsby stage, and it is possible that locations with subtle shade changes were not measured as separate subgrains. Further, the accuracy of that method is only $5^{\circ}$, so small variations in $c$-axis orientation between subgrains may not have been detectable or measurable.

\section{CONCLUSION}

Orientation data collected with EBSD have provided new information that will help us to better understand recrystallization in ice. The addition of accurate a-axis orientation demonstrates that the fabrics at the depths examined are not merely overall single-maximum fabrics, which would produce a random distribution of poles on the $\{11 \overline{2} 0\}$, but fabrics in which adjacent grains may share a axes (observed as clusters on the $\{11 \overline{2} 0\}$ pole figure). The misorientationangle histograms also illustrate the difference between an overall fabric (the random pair distribution) and nearestneighbor misorientation (the correlated data). In general, the ability to identify the location of nearest-neighbor poles on both the $\{0001\}$ and $\{11 \overline{2} 0\}$ pole figures allows clusters produced by polygonization to be distinguished from those produced by migration recrystallization. The statistically significant greater proportion of small misorientation angles $\left(1-5^{\circ}\right)$ between nearest neighbors strongly supports the presence of polygonization in this ice. In fact, it is the addition of a-axis information that specifically enables us to identify these as low-angle boundaries and suggests that they arise from rotations about axes perpendicular to the $c$ axis. This is consistent with the idea that the a axes correspond to tilt boundaries that form the basis of polygonization. The comparison of grain boundaries seen in thin sections with full grain orientation suggests that further investigation might yield even more information about recrystallization mechanisms in ice.

We expect EBSD to be useful in further studies of microstructural factors that affect recrystallization, such as grain-boundary impurities.

\section{ACKNOWLEDGEMENTS}

This research was supported by the US National Science Foundation (NSF) grant OPP-0440523 and US Army Research Office grant DAAD 19-03-1-0110. The views and conclusions contained herein are those of the authors and should not be interpreted as necessarily representing official policies, either expressed or implied, of the NSF, the Army Research Office or the US Government. The authors acknowledge the US National Snow and Ice Data Center, University of Colorado at Boulder, and the World Data Center-A for Paleoclimatology, US National Geophysical Data Center, Boulder, Colorado for providing data and D. Russell-Head and an anonymous referee for thoughtful comments that immeasurably improved this paper.

\section{REFERENCES}

Alley, R.B. 1988. Fabrics in polar ice sheets: development and prediction. Science, 240(4851), 493-495.

Alley, R.B., J.H. Perepezko and C.R. Bentley. 1986. Grain growth in polar ice: II. Application. J. Glaciol., 32(112), 425-433.

Alley, R.B., A.J. Gow and D.A. Meese. 1995. Mapping $c$-axis fabrics to study physical processes in ice. J. Glaciol., 41(137), 197-203.

Alley, R.B., A.J. Gow, D.A. Meese, J.J. Fitzpatrick, E.D. Waddington and J.F. Bolzan. 1997. Grain-scale processes, folding and stratigraphic disturbance in the GISP2 ice core. J. Geophys. Res., 102(C12), 26,819-26,830. 
Azuma, N. and A. Higashi. 1985. Formation processes of ice fabric pattern in ice sheets. Ann. Glaciol., 6, 130-134.

Azuma, N. and 6 others. 2000. Crystallographic analysis of the Dome Fuji ice core. In Hondoh, T., ed. Physics of ice core records. Sapporo, Hokkaido University Press, 45-61.

Bate, P.S., R.D. Knutsen, I. Brough and F.J. Humphreys. 2005. The characterization of low-angle boundaries by EBSD. J. Microsc. 220(1), 36-46.

Bender, M. and 6 others. 1994. Climate correlations between Greenland and Antarctica during the past 100,000 years. Nature, 372(6507), 663-666.

Budd, W.F. and T.H. Jacka. 1989. A review of ice rheology for ice sheet modelling. Cold Reg. Sci. Technol., 16(2), 107-144.

Castelnau, O., T. Thorsteinsson, J. Kipfstuhl, P. Duval and G.R. Canova. 1996. Modelling fabric development along the GRIP ice core, central Greenland. Ann. Glaciol., 23, 194-201.

Cheeney, R.F. 1983. Statistical methods in geology. London, George Allen and Unwin.

De La Chapelle, S., O. Castelnau, V. Lipenkov and P. Duval. 1998. Dynamic recrystallization and texture development in ice as revealed by the study of deep ice cores in Antarctica and Greenland. J. Geophys. Res., 103(B3), 5091-5105.

Duval, P. and O. Castelnau. 1995. Dynamic recrystallization of ice in polar ice sheets. J. Phys. IV (Paris), 5, Colloq. C3, 197-205. Supplément au 3.

Duval, P., M.F. Ashby and I. Anderman. 1983. Rate-controlling processes in the creep of polycrystalline ice. J. Phys. Chem. 87(21), 4066-4074.

Gow, A.J. and T. Williamson. 1976. Rheological implications of the internal structure and crystal fabrics of the West Antarctic ice sheet as revealed by deep core drilling at Byrd Station. CRREL Rep. 76-35.

Gow, A.J. and 6 others. 1997. Physical and structural properties of the Greenland Ice Sheet Project 2 ice cores: a review. J. Geophys. Res., 102(C12), 26,559-26,575.

Hansen, D.P. and L.A. Wilen. 2002. Performance and applications of an automated c-axis ice-fabric analyzer. J. Glaciol., 48(160), 159-170.

Herron, S.L., C.C. Langway, Jr and K.A. Brugger. 1985. Ultrasonic velocities and crystalline anisotropy in the ice core from Dye 3, Greenland. In Langway, C.C., Jr, H. Oeschger and W. Dansgaard, eds. Greenland ice core: geophysics, geochemistry, and the environment. Washington, DC, American Geophysical Union, 23-31. (Geophysical Monograph 33.)

Hondoh, T. 2000. Nature and behavior of dislocations in ice. In Hondoh, T., ed. Physics of ice core records. Sapporo, Hokkaido University Press, 3-24.

Iliescu, D., I. Baker and H. Chang. 2004. Determining the orientation of ice crystals using electron backscatter patterns. Microsc. Res. Techn., 63, 183-187.

Kasper, J.S. and K. Lonsdale, eds. 1959. International tables for x-ray crystallography, vol. II: mathematical tables. Birmingham, Kynoch Press.

Langway, C.C., Jr. 1958. Ice fabrics and the universal stage. SIPRE Tech. Rep. 62.

Lindley, D.V. and W.F. Scott. 1995. New Cambridge statistical tables. Second edition. Cambridge, Cambridge University Press.

Lloyd, G.E. and B. Freeman. 1994. Dynamic recrystallization of quartz under greenschist conditions. J. Struct. Geol., 16(6), 867-881.

Lloyd, G.E., A.B. Farmer and D. Mainprice. 1997. Misorientation analysis and the formation and orientation of subgrain and grain boundaries. Tectonophysics, 279(1-4), 55-78.
Mackenzie, J.K. 1958. Second paper on statistics associated with the random disorientation of cubes. Biometrika, 45, 229-240.

Matsuda, M. 1979. Determination of a-axis orientations of polycrystalline ice. J. Glaciol., 22(86), 165-169.

Matsuda, M. and G. Wakahama. 1978. Crystallographic structure of polycrystalline ice. J. Glaciol., 21(85), 607-620.

Mayewski, P.A. and 6 others. 1997. Major features and forcing of high-latitude Northern Hemisphere atmospheric circulation using a 110,000-year-long glaciochemical series. J. Geophys. Res., 102(C12), 26,345-26,366.

Meese, D.A. and 8 others. 1994. Preliminary depth-age scale of the GISP2 ice core. CRREL Spec. Rep. 94-1.

Meese, D.A. and 8 others. 1997. The Greenland Ice Sheet Project 2 depth-age scale: methods and results. J. Geophys. Res., 102(C12), 26,411-26,423.

Morawiec, A. 1995. Misorientation-angle distribution of randomly oriented symmetric objects. J. Appl. Cryst., 28(3), 289-293.

Mori, Y., T. Hondoh and A. Higashi. 1985. Development of an automatic ice fabric analyser. Ann. Glaciol., 6, 281-283.

National Snow and Ice Data Center (NSIDC). 1997. The Greenland Summit ice cores. Boulder, CO, University of Colorado. Cooperative Institute for Research in Environmental Sciences. National Snow and Ice Data Center. CD-ROM.

Obbard, R., I. Baker and D. Iliescu. 2006. Correspondence. Grain boundary grooving in ice in a scanning electron microscope. J. Glaciol., 52(176), 169-172.

Porter, D.A. and K.E. Easterling. 1993. Phase transformations in metals and alloys. Second edition. London and New York, Chapman \& Hall.

Randle, V. and O. Engler. 2000. Introduction to texture analysis: macrotexture, microtexture and orientation mapping. Amsterdam, Gordon and Breach.

Russell-Head, D.S. and C.J.L. Wilson. 2001. Automated fabric analyser system for quartz and ice. Geol. Soc. Austral. Abstr., 64, 159.

Thorsteinsson, T., J. Kipfstuhl and H. Miller. 1997. Textures and fabrics in the GRIP ice core. J. Geophys. Res., 102(C12), 26,583-26,599.

Wang, Y. and N. Azuma. 1999. A new automatic ice-fabric analyzer which uses image-analysis techniques. Ann. Glaciol., 29, 155-162.

Wheeler, J., D.J. Prior, Z. Jiang, R. Spiess and P.W. Trimby. 2001. The petrological significance of misorientations between grains. Contribs. Mineral. Petrol., 141, 109-124.

Wilen, L.A. 2000. A new technique for ice-fabric analysis. J. Glaciol., 46(152), 129-139.

Wilen, L., C. Di Prinzio and S. Hurley. 2002. Application of novel fabric and texture analysis techniques to GISP2. EOS Trans. AGU, 83(47), Fall Meeting Suppl., Abstract C62A-0910.

Wilen, L.A., C.L. DiPrinzio, R.B. Alley and N. Azuma. 2003. Development, principles, and applications of automated ice fabric analyzers. Microsc. Res. Techn., 62(1), 2-18.

Wilson, C.J.L., D.S. Russell-Head and H.M. Sim. 2003. The application of an automated fabric analyzer system to the textural evolution of folded ice layers in shear zones. Ann. Glaciol., 37, 7-17.

Wolff, E.W. and J.G. Paren. 1984. A two-phase model of electrical conduction in polar ice sheets. J. Geophys. Res., 89(B11), 9433-9438.

Yang, Q. and 7 others. 1995. A global perspective of nitrate flux in ice cores. J. Geophys. Res., 100(D3), 5113-5121. 